\title{
Evolución Urbana y Arquitectónica de la Ciudad de Matagalpa
}

Urban and Architectural Evolution of the City of Matagalpa

Cardoza Sánchez, Uriel Ramón

urcardoza@uni.edu.ni

ARQUITECTO, Docente Titular de la Facultad de Arquitectura - UNI,

Nicaragua

\begin{abstract}
The territory of north central Nicaragua has valuable natural and cultural attributes that characterize the historical and cultural identity of Matagalpa, these attributes must conform as a basis for sustainable development for its people, for which it is necessary among other things update the regulatory legal framework heritage in Nicaragua and further develop the requirements for a tourist product of international quality, but first must build the historiographical basis in general and particularly that of Matagalpa, which fuel the main object of this work.

Keywords

Territory, heritage, history, culture, Matagalpa.

\section{Resumen}

El territorio del centro-norte de Nicaragua tiene valiosos atributos naturales y culturales que caracterizan la identidad histórica y cultural de Matagalpa, estos atributos deben conformarse como base para el desarrollo sustentable de su población, para lo cual es necesario, entre otras cosas, En Nicaragua y desarrollar aún más los requisitos para un producto turístico de calidad internacional, pero primero debe construir la base historiográfica en general y en particular la de Matagalpa, que alimentan el objeto principal de esta obra.
\end{abstract}

Palabras claves

Territorio, patrimonio, historia, cultura, Matagalpa.

\section{Introducción}

El patrimonio cultural y natural de la región centro americana y particularmente de Nicaragua es aún poco conocido a nivel global, sobre todo desde la perspectiva de un análisis integral del territorio.

El desarrollo del territorio norte de Nicaragua y particularmente la ciudad de Matagalpa, así como la identificación y divulgación de su patrimonio ha sido muy limitado, a pesar de que después de las ciudades de León y Granada guarda una de las historias de mayor valor cultural del país; habiendo sido base de una aguerrida población indígena, la cual opuso permanente 
Arquitectura +

ISSN: 2518-2943

www.revistas.uni.edu.ni/index.php?journ

$\mathrm{al}=$ arquitectura
Vol. 2- Número 3 / Junio 2017

Evolución Urbana y Arquitectónica de la Ciudad de Matagalpa

Cardoza Sánchez, Uriel Ramón urcardoza@uni.edu.ni

resistencia ante la colonización española aun avanzado el siglo XIX, y que también realizo un gran aporte en la defensa del territorio nacional durante la guerra de independencia.

A pesar de esto, no se encuentra literatura científica que documente estos valores patrimoniales naturales y urbanos arquitectónicos que contribuyen a la identidad cultural de sus habitantes, lo que si se ha desarrollado únicamente en las ciudades que tuvieron mayor influencia española en su desarrollo, como lo son León, Granada y muy recientemente Masaya.

Por esto, el objeto o problema particular de esta investigación es la historia del territorio rural y urbano de Matagalpa, realizando una sistematización de los datos disponibles de la evolución del territorio y la ciudad en el tiempo, además de la recopilación y ordenamiento de fotografías antiguas y actuales que evidencien los cambios y las permanencias de las formas urbanas y arquitectónicas que en la memoria de sus habitantes subsisten o han desaparecido.

\section{Materiales y Métodos}

Los recursos y materiales utilizados para esta investigación fueron principalmente de fuentes primarias: libros, revistas, diarios, mapas y fotografías, además de entrevistas como parte de un trabajo monográfico para optar al título de arquitecto dirigido por el autor. No se encontraron artículos científicos respecto a la historia y la evolución del territorio y la ciudad objeto de este trabajo.

Por tanto el desarrollo de la investigación desde el punto de vista metodológico partió del método general de la investigación social que es la investigación documental, la que según Baena (1985) es una técnica que consiste en la selección y recopilación de información por medio de la lectura y crítica de documentos y materiales bibliográficos, de bibliotecas, hemerotecas, centros de documentación e información y se desarrolla en cuatro momentos:

- $\quad$ Planeación

- Colección de Información

- Organización, Análisis e Interpretación

- $\quad$ Presentación de Resultados

El proceso de investigación documental, luego de los cuatro momentos en mención, da como producto diferentes tipos de trabajos documentales y en este caso se logra una compilación que integra y relaciona materiales dispersos elaborados por diversos autores, sistematizados cronológicamente y vinculados a la memoria urbana y arquitectónica de los habitantes del lugar.

\section{Resultados y Discusión}

La ciudad de Matagalpa se conformó en el tiempo sobre el asentamiento indígena original entre el rio grande de Matagalpa y el cerro de apante, posibilitando un paisaje cultural y natural urbano arquitectónico integrado a su topografía natural generando grandes remates visuales en sus bocas 
calles. Fue capital temporal durante la guerra de independencia y a través del tiempo ha visto nacer grandes figuras de la política y la cultura nacional.

El centro norte de Nicaragua muestra en los nombres de sus lugares y poblados la evidencia lingüística de los indígenas Matagalpas que dejaron como herencia una gran cantidad de vocablos para identificar los grandes atributos naturales de los lugares que habitaron antes de la llegada de los españoles. Estos atributos naturales dieron el escenario idóneo para que nuestros indígenas se asentaran y que luego los europeos encontraran, integrándose o no al hábitat autóctono de lo que hoy es el centro norte de Nicaragua y particularmente la ciudad de Matagalpa.

Se conoce que hacia el año 595 D.C. se realizó la primera invasión de los indios Chorotegas, provenientes de México al territorio actual de Nicaragua, entre los cuales se considera estaban los primeros pobladores de la región de Matagalpa, estos también conocidos como Choroteganos, tribus de origen mejicano que inmigraron a Centro América, su idioma era el Nahualt del cual se desprende el Matagalpa como lengua propia.

En este sentido etimológicamente el nombre de Matagalpa se extrae del Nahualt (matlatp-Red, calli-Casas, pan; Lugar; Matlactli-calli-pan; Matlatl -galpa) interpretándose de diferentes maneras: "La Casa de las Redes”, “En las diez casas o familias”, o "Tierra de Honderos”.

\section{Época Virreinal}

\section{Siglo XVI}

Hacia 1502 se documenta la llegada de los españoles a Nicaragua, fundando las primeras ciudades en el año de 1524, estas fueron Granada y León, debido a que el ingreso español se dio por la costa nicaragüense del océano pacífico. A partir de estas ciudades se desarrollaron las expediciones de conquista del resto del territorio que hoy ocupa Nicaragua generando con ello la fundación de nuevas ciudades y la reducción y poblamiento de asentamientos indígenas autóctonos.

En 1527 el teniente español Gabriel de Rojas desarrollando una expedición buscando el Desaguadero al Atlántico en una ruta por el norte descubre el pueblo indígena de Cihua-coatl, conocido después como Sebaco. Esta población era habitada por indios Matagalpas los que practicaban culto a la diosa conocida como Mujer Serpiente, este nombre traducido del Nahualt por intérpretes chorotegas o su nombre en lengua Matagalpa o Cacaopera se considera perdido en el tiempo.

Según el reporte del Gobernador Pedro de los Ríos en 1543 Francisco de Castañeda funda a treinta leguas de la ciudad de León la población de la Nueva Segovia, la cual incluía poblados del territorio norte de Nicaragua Taguangalpa, Santa María de Tologalpa, y Sebaco.

Ya en 1560 se conoce sobre la concesión de la Parcialidad india de Molaguina como Encomienda a Alonso Quintero, por parte del Rey de España, lo que se consideraría el primer 
reporte escrito sobre parte del asentamiento indígena que posteriormente se conocería como Matagalpa, evidentemente este asentamiento indígena ya había sido reducido por los españoles, aunque no se encuentra una fecha de fundación como poblado.

\section{Siglo XVII}

En 1603 diecisiete pueblos indígenas de la Segovia se hallan sometidos al poder español, entre los cuales se reporta que los españoles reclutan indios de los pueblos de Molaguina y Solingalpa para llevarlos al Valle de Olancho, Honduras en expedición punitiva contra los Jicaques de la Tologalpa que habían arrasado con el vecino pueblo de Poteca. Lo cual es una primera evidencia de los atributos guerreros de los indios Matagalpas.

En 1606 el Fraile Mercedario Juan de Albuquerque desde Sebaco descubre una entrada a las montañas de Tabavaca (Muimui y Musun). Este hecho podría definir la llegada de los Mercedarios a las Parcialidades de Molaguina y Solingalpa y por ende el inicio de la construcción del Convento de la Merced, ya que posteriormente en el año de 1608, se conoce que el Comendador del Convento de la Merced del Pueblo de Matagalpa sale en misión hacia Muimui, llevando de interprete a Don Diego, Cacique de Molaguina, indio cristiano de la encomienda de Hernando de Espino logra bautizar ente otros a Xpilon, Cacique de Muimui.

Encontramos aquí la primera referencia documentada del Pueblo de Matagalpa como tal, aunque se sigue identificando como líder de los indígenas al Cacique de Molaguina. Otro aspecto a identificar es que posiblemente en estos años también se debió iniciar la construcción de la primera Ermita o Iglesia de Matagalpa, seguramente como parte del Convento Mercedario.

En 1624 Fray Juan Godoy fundaba la reducción de San Ramón Nonato, cerca de Matagalpa. En 1632 se crea por la Real Audiencia de Guatemala el Corregimiento de Matagalpa, designándose la población de este nombre como asiento del corregidor. Al mismo tiempo se crean los Corregimientos de El Realejo, Monimbo, Chontales y Quesalguaque. Para este tiempo Nicaragua era ya considerada una Provincia.

En 1679 se da una primera respuesta de inconformidad por parte de los indígenas por los abusos Fray Diego de Diéguez expulsándolo de Matagalpa. Desembocando este problema en 1688 cuando los indios de Matagalpa, Molaguina, Solingalpa, Jinotega y Muimui abandonan sus pueblos dejando dos papeles de protesta por el maltrato por parte de corregidores y vecinos.

\section{Siglo XVIII}

En 1700 se reporta el inicio de la construcción de una Iglesia dedicada a San José en el Pueblo de San Pedro de Matagalpa, primera referencia del poblado de Matagalpa como pueblo aparentemente fundado por españoles, sin definir en cuál de las parcialidades indígenas estaría ubicada dicha iglesia. Hasta este momento se identifican apenas dos hitos arquitectónicos en el poblado, el Convento Mercedario y la Iglesia de San José, quedando siempre la interrogante si con el convento no se construyó una primera iglesia. 
Durante la visita pastoral en 1752 de Fray Agustín Morel de Santa Cruz dice en su carta informe que el pueblo de Matagalpa se compone de tres parcialidades: Matagalpa, Solingalpa y Molaguina, diciendo además que habían ladinos y laboríos, aludiendo posiblemente al futuro barrio de Laborío. En dicha carta encontramos evidencia de la conformación urbana inicial de la Ciudad de Matagalpa, particularmente india, destacando que se encuentra en un terreno desigual y sinuoso, muy fértil y fresco a media legua de la Montaña. Lo que refiere seguramente la topografía variada del lugar y a la cercanía del Cerro de Apante y San Salvador entre otros. No refiere la existencia del Rio Grande a la par del poblado:

*Pasadas ocho leguas, cuatro de ellas algo trabajosas, llegué al pueblo de Matagalpa. Hallase situado a media legua de la montaña en un terreno desigual y montuoso, pero muy fértil y fresco. Componese de tres parcialidades de indios, la primera lleva el nombre del mismo pueblo, la segunda el de Solingalpa y la tercera el de Molagüina“.

Nos describe además los hitos arquitectónicos religiosos que ya poseía el pueblo: la Iglesia Parroquial en la Parcialidad de Matagalpa mostrando la importancia de esta, además nos permite identificar su estructura y forma constructiva, con la particularidad funcional de albergar la residencia del cura párroco, un religioso mercedario, sin mencionar la existencia supuesta de un Convento Mercedario, al cual se hace referencia anteriormente en 1608.

En la de Matagalpa está la iglesia parroquial; su titular San Pedro, es de tres naves, la primera sobre horcones y el techo entablado, las otras dos lo tienen de caña y las paredes de cal y piedra, en ellas reside el párroco, que es un religioso mercedario, corre a su cargo no sólo la administración de este pueblo y el de Sebaco, como he dicho, sino también la de Muimui y Jinotega, las de Solingalpa y Molagüina, tienen ermitas de pajas, dedicadas a Santa Ana y Santiago, con sacristía reducida y un altar muy pobre, fuera de estas tres parcialidades, hay así mismo ladinos y laboríos que son los indios forasteros.

Luego del reporte del Obispo Morel de Santa Cruz en 1760 Frailes Mercedarios fundaron una reducción con el nombre sumo de Guanuca (casa de cenizas o de las casas quemadas), poblado con caribes extraídos de las montañas del oriente de Matiguas y del Cerro del Musun. No formo parte del pueblo indígena de Matagalpa y estuvo asentado entre el altiplano de las minitas y la cañada de Los Congos. Posteriormente se reporta que en 1770 José Antonio Vargas, Capitán de Conquista, solicita a Guatemala terreno inmediato al Pueblo de Matagalpa para poblarlo con Caribes que sacaron de las Montañas, creando así Guanuca, ya como parte del Pueblo dando continuidad a la iniciativa de los Frailes Mercedarios.

Es posible en este punto deducir y graficar el emplazamiento original de los asentamientos primeros de los Indios Matagalpa, Españoles y además los Caribes, conformando la Estructura Urbana original de la actual ciudad de Matagalpa, que con los años fue compactándose cultural, social y físicamente entre importantes atributos naturales: el Rio Grande de Matagalpa, el Cerro de Apante y las Quebradas o Chuisles de Guanuca, Yaguare, y Apante. 
Esta primera conformación urbana se puede describir así:

a) La Parcialidad de Matagalpa entre el río de su nombre y la quebrada de Guanuca.

b) La Parcialidad de Solingalpa y su posterior sección de "Pueblo Grande" comprendida entre las quebradas de Guanuca y Yaguares.

c) La Parcialidad de Molaguina se ubicó entre la quebrada de Yaguares y la de Apante.

d) La Parcialidad de Laborío al sur y occidente de la quebrada de Apante.

En 1767 ya se referían al Partido de Matagalpa como el mayor tributario de la Provincia de Nicaragua, aunque no se detalla en base a que se lograba ese tributo, aparte del trabajo de los indígenas. Ya en 1773 el entonces Corregidor de Matagalpa Don Juan de la Roca reporta nuevamente una sublevación de los indios, al igual que en Jinotega en 1777 y 1786.

Según el Compendio de la Historia de la Ciudad de Guatemala hacia 1778 Nicaragua se consideraba la cuarta provincia del Reino, y como Intendencia según las ordenanzas reales para el buen gobierno de las colonias españolas de América, contenía cinco partidos; donde León tenía título de gobierno y luego El Realejo, Subtiava, Matagalpa y Nicoya eran Corregimientos, dichos cantones estaban bajo la jurisdicción del Intendente de la Provincia, el cual tenía seis sub delegados, uno en la ciudad de Segovia, uno en la Villa de El Realejo y uno cada uno en los pueblos de Subtiava, Matagalpa, Masaya y Nicoya. En cuanto a lo religioso estaban el cuido del Señor Obispo de León.

Matagalpa como partido, en conjunto con Chontales, es descrito en esta época con límite Norte la Nueva Segovia, al Oeste con el Gobierno de León, por el Sur con el Rio San Juan, y por el Este y Noroeste con la Provincia de Tologalpa. Describiéndose como productora de ganado vacuno, maíz, frijoles y otros frutos; contando con 20,000 vecinos en 12 poblados y muchas haciendas, formado además por tres curatos, uno de ellos administra la religión de Nuestra Señora de la Merced, y los otros dos clérigos seculares. Evidentemente el de Nuestra Señora de la Merced se refería al entonces poblado de Matagalpa antes descrito y que mostraba seguramente las bases de la que hoy es su Catedral. Estos datos aclaran porque entonces el territorio del Partido de Matagalpa era considerado el mayor tributario de la Provincia de Nicaragua.

\section{Siglo XIX}

En 1803, se tiene referencia de la continuidad de quizás el principal hito arquitectónico del floreciente pueblo Matagalpa, del cual reporta en 1752 Fray Morel de Santa Cruz su primitiva existencia, la Iglesia Parroquial de San Pedro ubicada en la Parcialidad de Matagalpa o Pueblo Grande. Dicha Iglesia se puede ubicar como resultado de las obras de los Padres Mercedarios, a la par de su Convento, ya que en el Arco Toral de la actual Catedral se puede ver esta fecha como indicación de su terminación, al menos de una segunda construcción que por el crecimiento de los feligreses del poblado, seguramente hubo que ampliar. Esta segunda Iglesia 
Arquitectura +

ISSN: 2518-2943

www.revistas.uni.edu.ni/index.php?journ

$\mathrm{al}=$ arquitectura
Vol. 2- Número 3 / Junio 2017

Evolución Urbana y Arquitectónica de la Ciudad de Matagalpa

Cardoza Sánchez, Uriel Ramón urcardoza@uni.edu.ni

pudo haberse iniciado por el año 1760. En 1808 se descubren los primeros yacimientos de oro cerca del poblado de San Ramón Nonato, a muy pocas leguas de Matagalpa.

Hacia 1816 se confirma que el pueblo de Matagalpa, con 1492 habitantes, se divide en cuatro parcialidades: Laborío 447, Matagalpa o Pueblo Grande 379, Solingalpa 323 y Molaguina 343. Nótese que la más reciente parcialidad tiene la mayor cantidad de habitantes y no se reporta la reducción creada por los Mercedarios e integrada al poblado por el Capitán de la Conquista en 1670, Guanuca.

La Provincia de Nicaragua emite como tal, su primera Constitución Política, el 8 de abril de 1826. En dicha constitución se lee que el territorio de Nicaragua comprendía aun nueve partidos, entre los que siempre estuvo el Partido de Matagalpa; a continuación se ordena que el territorio sea dividido en Departamentos, quedando en ese momento el Partido de Matagalpa como parte del Departamento de Segovia.

El 30 de abril de 1838 el Estado de Nicaragua se separa definitivamente de la Federación de Centroamérica, por lo que el 12 de noviembre del mismo año al dictarse la primera Constitución del Estado libre y Soberano de Nicaragua se transforma la división del territorio en Departamentos y Distritos. El 21 de diciembre del mismo año se establecen cuatro Departamentos, entre los que encontramos el de Septentrión conformado por los distritos de Segovia y Matagalpa, desapareciendo temporalmente Matagalpa como Departamento.

El 30 de Abril de 1854 Nicaragua se transforma en República manteniéndose la división territorial antes mencionada hasta después de la trágica guerra nacional o guerra civil entre Democráticos de León (Liberales) y Legitimistas de Granada (Conservadores), en la cual Matagalpa y sus Comarcas se suman a los Legitimistas, a pesar de haber mantenido mayor vinculo histórico con León.

El 19 de agosto de 1858 se emite una nueva constitución en base a la cual, el 30 de Agosto del mismo año se divide el territorio nacional en siete departamentos, restableciendo de manera definitiva entre ellos al Departamento de Matagalpa, manteniendo el mismo nombre en su cabecera, Villa de San Pedro de Matagalpa, la que finalmente el 14 de Febrero de 1862 es elevada a la categoría de ciudad.

\section{Conclusiones}

No queda duda de la importancia histórica y cultural del territorio de Matagalpa a partir de su origen indígena, sus atributos naturales y su posterior mezcla multirracial, lo que ha permitido a través del tiempo definir una identidad propia que caracteriza a sus habitantes y que fundamenta la urgente necesidad de documentar sus valores históricos naturales y culturales, para su difusión y consiguiente conservación. 
Arquitectura +

ISSN: 2518-2943

www.revistas.uni.edu.ni/index.php?journ

$\mathrm{al}=$ arquitectura
Vol. 2- Número 3 / Junio 2017

Evolución Urbana y Arquitectónica de la Ciudad de Matagalpa

Cardoza Sánchez, Uriel Ramón urcardoza@uni.edu.ni

Con el presente trabajo se ha logrado avanzar en la construcción de la historiografía del territorio rural y urbano del centro norte de Nicaragua, particularmente la ciudad de Matagalpa que hasta el momento no cuenta con literatura académica ni científica que permita contribuir a la educación formal y no formal sobre los valores históricos y culturales que conforman el patrimonio local de esta porción de montañosa de Nicaragua que está siendo explotada turísticamente sin respaldo didáctico de los hechos que en el tiempo han conformado la identidad cultural de esta población.

Se logra el objetivo planteado al inicio de este trabajo de forma que pueda ser utilizado por la sociedad en general a fin de conservar y gestionar su patrimonio cultural en general de manera institucional y sobre todo con la participación de la comunidad Matagalpa que conociendo su origen y su evolución histórica podrá contribuir a completar esta iniciativa académica.

\section{Agradecimientos}

Este trabajo fue posible al apoyo recibido de parte de la Asociación Universitaria Iberoamericana de Posgrados AUIP como institución que financio mis estudios de Doctorado en Gestión y Conservación del Patrimonio, además del arduo trabajo literario desarrollado por el Ing. Eddy Khul sobre la historia de Matagalpa en diversas facetas de su sociedad y culturas diversas.

\section{Referencias}

1. Guerrero, Julián N. y Soriano, Lola (1964) / Monografía del Departamento de Matagalpa, Banco Central de Nicaragua.

2. Cardoza, Blanca Rosa (1998) / Evolución Urbano Arquitectónica de la Ciudad de Matagalpa, Trabajo Monográfico para optar al título de Arquitecto / Escuela de Arquitectura, Universidad Católica Redemptoris Mater UNICA.

3. Cardoza S, Uriel R. (1999) / Diagnóstico Ambiental Turístico del Municipio de Matagalpa, /Tesina para optar al Título de Especialista en Turismo y Gestión Ambiental / Programa de Estudios Ambientales Urbano Territoriales PEA-UT Universidad Nacional de Ingeniería UNI.

4. Kuhl, Eddy (2002) / Matagalpa Histórica.

5. Vogl Baldizon, Alberto / Nicaragua con amor y humor / Ministerio de Cultura, 1985. (Primera edición 1977).

6. Boletín Nicaragüense de Bibliografía y Documentación: Monografía de Matagalpa, editor Jorge Eduardo Arellano, No. 125 octubre-diciembre 2004.

7. Historia del Istmo Centroamericano, tomos i y ii, coordinación cultural y educativa centro americana, varios autores. Año 2000. 